\title{
G-CSF and Erythropoietin Combination Therapy for Infarct Repair: Two Plus Two Equals Two?
}

\author{
Editorial to: "Cytokine Combination Theray with Erythropoietin and Granulocyte \\ Colony Stimulating Factor in a Porcine Model of Acute Myocardial Infarction" by F.S. \\ Angeli et al.
}

\section{Carrie M. Quinn • Buddhadeb Dawn}

Published online: 1 October 2010

(C) Springer Science+Business Media, LLC 2010

In the first study of cytokine-induced bone marrow cell (BMC) mobilization and infarct repair, therapy with a combination of granulocyte-colony stimulating factor (G$\mathrm{CSF}$ ) and stem cell factor (SCF) improved survival, reduced infarct size, and improved left ventricular (LV) function and remodeling in mice after coronary ligation [1]. Since the publication of this seminal report, a number of cytokines/ growth factors have been utilized for cardiac repair with diverse dosage regimens and experimental conditions with variable results [2]. The studies of G-CSF therapy in clinical trials have also yielded divergent outcomes, and the results of recent meta-analyses suggest that G-CSF alone may not produce significant clinical benefits in unselected patients with acute myocardial infarction (MI) [3, 4]. As a result, the true utility of cytokine therapy for infarct repair remains largely unclear at this time, and further investigation is certainly warranted.

In this regard, Angeli and colleagues recently demonstrated the ability of G-CSF [5] and erythropoietin (EPO) [6] monotherapy to mobilize BMCs, enhance myocardial angiogenesis, reduce LV fibrosis, and preserve LV systolic function in a porcine model of acute MI. In the current issue of Cardiovascular Drugs and Therapy, these authors report data from a subsequent study that examined any potential additional benefit from combining G-CSF and EPO for infarct repair [7]. Although administration of G-CSF and EPO after MI resulted in improved LV systolic function, when compared with historical data from the previous

\section{M. Quinn • B. Dawn $(\bowtie)$}

Division of Cardiovascular Diseases and Cardiovascular Research Institute, University of Kansas Medical Center and Hospital, 3901 Rainbow Blvd, Rm. 1001, Eaton Hall, MS 3006, Kansas City, KS 66160, USA

e-mail: bdawn@kumc.edu studies $[5,6]$, the current benefits with a combinatorial therapy were not significantly greater than those achieved with monotherapy with either cytokine [7]. These results are important as they have distinct implications for the design of future clinical trials of cytokine therapy. These results also underscore that our understanding of the mechanisms through which cytokines may exert cardiac reparative benefits remains incomplete.

Recent studies have shown that EPO, a cytokine for the erythroid progenitors, can exert cardioprotective effects resulting in reduced infarct size, reduced apoptosis, and improved LV function following myocardial ischemic injury [8]. These actions arise, at least in part, from the activation of a transmembrane EPO receptor (EPOR), which belongs to the cytokine receptor Type I superfamily and is expressed on multiple cell types, including cardiomyocytes. EPOR activation leads to phosphorylation of receptor-associated JAK2, resulting in activation of a multitude of signaling pathways, including PI3-K/Akt, MAPK, and STAT pathways [9]. The activation of these pathways results in upregulation of antiapoptotic proteins, inhibition of caspase activation, and increase in endothelial nitric oxide synthase (eNOS) expression, which collectively prevent apoptosis in the ischemic myocardium $[8,10]$.

Another potential mechanism via which EPO may contribute to myocyte salvage and improved remodeling is the induction of new vessel formation with enhanced oxygen delivery to the infarct border zone [11]. Indeed, EPO therapy has been shown to increase capillary density, decrease periinfarct fibrosis, attenuate LV hypertrophy, and improve LV function [11, 12]. Recent studies indicate that upregulation of myocardial expression of vascular endothelial growth factor, a potent angiogenic molecule, also contributes toward EPO-induced improvement in myocar- 
dial vascularity [13]. Importantly, EPO can mobilize endogenous BMCs, which may home to the injured myocardium and attenuate $\mathrm{LV}$ remodeling and dysfunction. In this context, the ability of EPO to mobilize endothelial progenitor cells (EPCs) may partly account for the observed neovascularization [13].

While preclinical data have consistently supported the efficacy of EPO, experimental research and early clinical trials exploring the benefits of GCSF monotherapy in acute MI have generated more disparate conclusions [3, 14, 15]. A hematopoietic cytokine, GCSF regulates the maturation, survival, proliferation, and functional activation of granulocytes and effectively mobilizes BMCs to the peripheral circulation [16]. Similar to EPOR, G-CSF receptors are present on cardiomyocytes, and when activated, inhibit apoptosis via activation of the JAK/STAT pathway [17]. GCSF administration at the onset of reperfusion can also activate the Akt/eNOS pathway leading to increased NO production and reduced infarct size [18]. In addition, GCSF-induced neovascularization may play an important role in infarct repair and preservation of myocardial contractility $[14,17]$. Although these mechanistic underpinnings quite appropriately predict improved outcomes, GCSF monotherapy failed to result in significant cardiac reparative benefits in several studies in animals as well as humans [3, 15, 19-21]. In contrast, combination therapies with G-CSF and another cytokine (SCF or Flt-3 ligand) resulted in improved structural and functional benefits in mouse models of acute MI $[1,15]$.

However, because of the differences in G-CSF dosage and regimen among studies, it is not clear whether the actions of G-CSF in pigs mimic those in mice. With G-CSF alone, improved outcomes [5, 14], no benefit on LV function [22, 23], and even a detrimental effect with delayed G-CSF treatment [24] have all been reported. The current study is the first to report data from the G-CSF/EPO combination therapy in pigs, and several potential reasons may be invoked to explain the failure of this regimen to produce additive benefits. First, given the similarities between the mechanisms of myocyte salvage with these two agents (activation of antiapoptotic signaling, induction of angiogenesis, direct cytoprotective effects, and such), it is possible that these outcomes are already maximized with therapy with either agent. To examine this possibility and generate specific information, quantitative assessment of molecular pathway activation and myocyte apoptosis will be necessary. Second, daily administration of G-CSF along with other cytokines in previous studies resulted in substantial mobilization of BMCs with significant myocardial homing and improved outcomes $[1,15]$. Although the G-CSF regimen used in this study was interrupted and somewhat different (days 0 and 5-9) from regimens in previous studies, the current data indicate that G-CSF/EPO combination results in mobilization of greater numbers of BMCs compared with monotherapy [5-7]. However, in order to explain the current observations, it will be necessary to examine and compare the type of BMCs (for example, EPCs) mobilized with these different regimens, and whether mobilized cells indeed homed to the myocardium. Third, although the outcomes regarding LV systolic function were not improved with G-CSF/EPO vs. single agents, the combination therapy improved LV diastolic function [7], which was not affected by monotherapy with either agent $[5$, 6]. These observations highlight the importance of looking beyond the conventional parameters of cardiac repair assessment as the advantages of one therapy over another become increasingly incremental. Finally, as the authors acknowledge, the follow-up duration was not sufficiently long to critically evaluate any potential benefit of combination therapy to be manifest during a longer follow-up.

Despite these uncertainties, the results from this first study of G-CSF/EPO combination in a large animal model of myocardial infarction provide considerable translational value. These results are even more important because clinical trials thus far have not shown any significant infarct-sparing effect of EPO monotherapy in the setting of a reperfused MI [25]. Since evidence of long-term benefits of G-CSF/EPO therapy on LV remodeling are currently lacking, future studies with longer follow-up will be necessary to generate essential information for therapeutic translation. The dosage and timing of cytokines will also need to be fine-tuned to identify potential advantages of combination cytokine therapy. Finally, to make the transition from experimental to clinical significance, demonstration of a sustained advantage over current therapies for MI will be necessary. Only through these systematic and painstaking approaches, the true utility of cytokine therapy for cardiac repair will be determined.

Acknowledgments This publication was supported in part by NIH grants R01 HL-89939 and R21 HL-89737, and the Maureen and Marvin Dunn endowment.

Conflict of interest None

\section{References}

1. Orlic D, Kajstura J, Chimenti S, Limana F, Jakoniuk I, Quaini F, et al. Mobilized bone marrow cells repair the infarcted heart, improving function and survival. Proc Natl Acad Sci USA. 2001;98:10344-9.

2. Brunner S, Engelmann MG, Franz WM. Stem cell mobilisation for myocardial repair. Expert Opin Biol Ther. 2008;8:1675-90.

3. Abdel-Latif A, Bolli R, Zuba-Surma EK, Tleyjeh IM, Hornung CA, Dawn B. Granulocyte colony-stimulating factor therapy for cardiac repair after acute myocardial infarction: a systematic review and meta-analysis of randomized controlled trials. Am Heart J. 2008;156:216-26.e9. 
4. Zohlnhofer D, Dibra A, Koppara T, de Waha A, Ripa RS, Kastrup $\mathrm{J}$, et al. Stem cell mobilization by granulocyte colony-stimulating factor for myocardial recovery after acute myocardial infarction: a meta-analysis. J Am Coll Cardiol. 2008;51:1429-37.

5. Angeli FS, Smith C, Amabile N, Shapiro M, Bartlett L, Virmani $\mathrm{R}$, et al. Granulocyte colony stimulating factor in myocardial infarction with low ejection fraction. Cytokine 2010;51:278-85.

6. Angeli FS, Amabile N, Burjonroppa S, Shapiro M, Bartlett L, Zhang $\mathrm{Y}$, et al. Prolonged therapy with erythropoietin is safe and prevents deterioration of left ventricular systolic function in a porcine model of myocardial infarction. J Card Fail. 2010;16:579-89.

7. Angeli FS, Amabile N, Shapiro M, Mirsky R, Bartlett L, Zhang Y, et al. Cytokine combination therapy with erythropoietin and granulocyte colony stimulating factor in a porcine model of acute myocardial infarction. Cardiovasc Drugs Ther. 2010;24:this issue.

8. Calvillo L, Latini R, Kajstura J, Leri A, Anversa P, Ghezzi P, et al. Recombinant human erythropoietin protects the myocardium from ischemia-reperfusion injury and promotes beneficial remodeling. Proc Natl Acad Sci USA. 2003;100:4802-6.

9. Ratajczak J, Majka M, Kijowski J, Baj M, Pan ZK, Marquez LA, et al. Biological significance of MAPK, AKT and JAK-STAT protein activation by various erythropoietic factors in normal human early erythroid cells. Br J Haematol. 2001;115:195-204.

10. Burger D, Lei M, Geoghegan-Morphet N, Lu X, Xenocostas A, Feng Q. Erythropoietin protects cardiomyocytes from apoptosis via up-regulation of endothelial nitric oxide synthase. Cardiovasc Res. 2006;72:51-9.

11. van der Meer P, Lipsic E, Henning RH, Boddeus K, van der Velden J, Voors AA, et al. Erythropoietin induces neovascularization and improves cardiac function in rats with heart failure after myocardial infarction. J Am Coll Cardiol. 2005;46:125-33.

12. Toma C, Letts DP, Tanabe M, Gorcsan 3rd J, Counihan PJ. Positive effect of darbepoetin on peri-infarction remodeling in a porcine model of myocardial ischemia-reperfusion. J Mol Cell Cardiol. 2007;43:130-6.

13. Westenbrink BD, Lipsic E, van der Meer P, van der Harst P, Oeseburg H, Du Marchie Sarvaas GJ, et al. Erythropoietin improves cardiac function through endothelial progenitor cell and vascular endothelial growth factor mediated neovascularization. Eur Heart J. 2007;28:2018-27.

14. Iwanaga K, Takano H, Ohtsuka M, Hasegawa H, Zou Y, Qin Y, et al. Effects of G-CSF on cardiac remodeling after acute myocardial infarction in swine. Biochem Biophys Res Commun. 2004;325:1353-9.
15. Dawn B, Guo Y, Rezazadeh A, Huang Y, Stein AB, Hunt G, et al. Postinfarct cytokine therapy regenerates cardiac tissue and improves left ventricular function. Circ Res. 2006;98:1098-105.

16. Demetri GD, Griffin JD. Granulocyte colony-stimulating factor and its receptor. Blood 1991;78:2791-808.

17. Harada M, Qin Y, Takano H, Minamino T, Zou Y, Toko H, et al. G-CSF prevents cardiac remodeling after myocardial infarction by activating the Jak-Stat pathway in cardiomyocytes. Nat Med. 2005;11:305-11.

18. Ueda K, Takano H, Hasegawa H, Niitsuma Y, Qin Y, Ohtsuka M, et al. Granulocyte colony stimulating factor directly inhibits myocardial ischemia-reperfusion injury through Akt-endothelial NO synthase pathway. Arterioscler Thromb Vasc Biol. 2006;26:e108-13.

19. Werneck-de-Castro JP, Costa ESRH, de Oliveira PF, PinhoRibeiro V, Mello DB, Pecanha R, et al. G-CSF does not improve systolic function in a rat model of acute myocardial infarction. Basic Res Cardiol. 2006;101:494-501.

20. Ripa RS, Jorgensen E, Wang Y, Thune JJ, Nilsson JC, Sondergaard L, et al. Stem cell mobilization induced by subcutaneous granulocytecolony stimulating factor to improve cardiac regeneration after acute ST-elevation myocardial infarction: result of the double-blind, randomized, placebo-controlled stem cells in myocardial infarction (STEMMI) trial. Circulation 2006;113:1983-92.

21. Zohlnhofer D, Ott I, Mehilli J, Schomig K, Michalk F, Ibrahim T, et al. Stem cell mobilization by granulocyte colony-stimulating factor in patients with acute myocardial infarction: a randomized controlled trial. JAMA 2006;295:1003-10.

22. Lee SS, Naqvi TZ, Forrester J, Cattley R, Shah A, Frantzen M, et al. The effect of granulocyte colony stimulating factor on regional and global myocardial function in the porcine infarct model. Int $\mathrm{J}$ Cardiol. 2007;116:225-30.

23. Sato T, Suzuki H, Kusuyama T, Omori Y, Soda T, Tsunoda F, et al. G-CSF after myocardial infarction accelerates angiogenesis and reduces fibrosis in swine. Int J Cardiol. 2008;127:166-73.

24. Beohar N, Flaherty JD, Davidson CJ, Vidovich M, Singhal S, Rapp JA, et al. Granulocyte-colony stimulating factor administration after myocardial infarction in a porcine ischemia-reperfusion model: functional and pathological effects of dose timing. Catheter Cardiovase Interv. 2007;69:257-66.

25. Binbrek AS, Rao NS, Al Khaja N, Assaqqaf J, Sobel BE. Erythropoietin to augment myocardial salvage induced by coronary thrombolysis in patients with ST segment elevation acute myocardial infarction. Am J Cardiol. 2009;104:1035-40. 